\title{
Movimentação financeira: a base de uma contribuição para o INSS em substituição à folha de pagamentos*
}

\author{
Marcos Cintra**
}

\begin{abstract}
SumÁRIo: 1. Introdução; 2. Regime previdenciário e bases de incidência; 3. Imposto sobre Valor Agregado (IVA) versus Imposto sobre Movimentação Financeira (IMF); 4. Comparativo dos impactos setoriais de uma Contribuição sobre Movimentação Financeira (CMF) com a atual contribuição patronal ao INSS; 5. A questão da cumulatividade; 6. Resumo das principais conclusões.
\end{abstract}

Summary: 1. Introduction; 2. Pension schemes and incidence bases; 3. IVA (Brazilian Value-Added Tax) versus IMF (Brazilian Financial Transaction Tax); 4. Comparison of the sectoral impacts of Contribution on Financial Movement (CMF) with the present patronly contribution to INSS; 5 . The issue of cumulativeness; 6 . Summarisation of the main conclusions.

Palavras chaves: tributo; imposto; movimentação financeira; cumulatividade; previdência social; folha de salários.

KEY WORDs: taxation; taxes; bank transactions tax; taxation of financial transactions; turnover tax; tax pyramiding; social insurance; payroll tax; withholding tax.

Em média, os salários no Brasil são onerados em 42,5\% do seu valor bruto, somandose a parte que é descontada do salário do trabalhador com a que incide sobre a folha de pagamentos das empresas. Isso torna o país uma das economias que mais tributam rendimentos do trabalho assalariado no mundo. O maior ônus sobre os salários recai sobre as empresas, estimulando práticas como a contratação de empregados sem carteira de trabalho assinada e a terceirização, fazendo da informalidade um dos elementos determinantes dos crescentes déficits do INSS. A folha de pagamentos é tributada em média em $35 \%$, sendo a contribuição previdenciária o tributo de maior

\footnotetext{
* Artigo recebido em jan. 2010 e aceito em ago. 2010.

* PhD em economia pela Universidade Harvard (EUA). Professor titular da Fundação Getulio Vargas. Deputado federal (1999-2003). Autor da proposta do Imposto Único. Endereço: Avenida Nove de Julho, 2.029/11ํ andar - CEP 01313-902, São Paulo, SP, Brasil. E-mail: mcintra@ marcoscintra.org.
} 
peso. Após diagnosticar o problema, este texto discute aspectos relacionados aos regimes previdenciários e as bases de incidência adequadas a cada um deles. Mostra ainda que o regime geral da previdência no Brasil assumiu conotação de política pública de renda complementar. Nesse sentido, propõe-se a substituição do INSS patronal, uma base restrita, por uma contribuição de $0,61 \%$ sobre as movimentações nas contas-correntes bancárias, uma base universal, e compara os efeitos sobre a economia de um tributo cumulativo com os produzidos por um imposto sobre o valor agregado. Utilizando o modelo de input-output de Leontief como mecanismo de análise, o trabalho revela que uma contribuição sobre as transações bancárias implica menor carga tributária sobre os preços setoriais e menor distorção alocativa que os $20 \%$ cobrados sobre a folha de salários das empresas para o INSS. Por fim, o texto procura desmistificar a crítica envolvendo a cumulatividade tributária.

Financial transaction: the basis for a contribution to the INSS, replacing the payroll

Wages and labor income are taxed in Brazil at the rate of $42.5 \%$ on the average, considering payments of both employers and employees. This makes it one of highest taxed labor markets in the world. The tax burden falls mostly on firms. Thus fact stimulates labor informality and outsourcing. This is one of the main reasons for the growing social security deficits. Payrolls are taxed in Brazil at the rate of approximately $35 \%$, and social security contributions account for most of burden. After diagnosing the problem, this essay discusses issues related to the social security regimes used in Brazil, and the various forms of financing most adequate to each of them. It is shown that the basic social security regime, called general social security regime, became a program quite similar to a public system of complementary income. As such, this paper proposes replacing the social security contributions made by firms, which have a restricted pattern of incidence, by a general contribution based of bank transactions with a rate of $0,61 \%$, which shows a universal pattern of incidence. It then compares the economic implications of such cumulative taxation with a conventional value added social security contribution. The analytical model is based on Leontief's input-output framework, and it shows that a contribution levied on bank transactions implies a lighter sectoral tax load on consumer prices, and less distortionary effects on alocation of resources, than the revenue equivalent contribution of $20 \%$ on payrolls presently in use. This paper attempts to show tax pyramiding may not have such harmful economic effects as usually assumed by critics of cumulative taxation.

\section{Introdução}

O objetivo deste texto é discutir a adoção da movimentação financeira como base de incidência alternativa à contribuição patronal ao Instituto Nacional do Seguro Social (INSS) cobrada sobre a folha de pagamentos das empresas. 
Trata-se de um novo modelo de financiamento para o RGPS (Regime Geral da Previdência Social), cuja principal fonte de recursos, a contribuição patronal, é o maior ônus tributário sobre os salários no Brasil.

Conforme exposto na Tabela 1, o Brasil impõe pesada carga tributária sobre os salários dos setores formais da economia. Como ocorre em situações de substitubilidade de fatores de produção, a imposição de elevado custo tributário sobre a folha de pagamento das empresas faz com que haja:

a) substituição de mão de obra por outros fatores, e

b) substituição do emprego formal por serviços laborais oriundos do setor informal ou terceirizados.

\section{Tabela 1}

Tributação sobre salários no Brasil em 2005 (\% do salário bruto)

\begin{tabular}{|lccc|}
\hline Salários mínimos & Empregado (1) & Empregador (2) & Total \\
\hline Até 2 & 7,65 & 31,50 & 39,15 \\
2 a 3 & 8,65 & 31,50 & 40,15 \\
3 a 5 & 10,57 & 32,60 & 43,17 \\
5 a 6 & 15,42 & 32,60 & 48,02 \\
6 a 8 & 17,27 & 32,60 & 49,87 \\
8 a 10 & 21,26 & 33,17 & 54,43 \\
10 a 15 & 22,92 & 33,17 & 56,09 \\
15 a 20 & 24,23 & 33,17 & 57,40 \\
20 a 30 & 25,21 & 33,98 & 59,19 \\
30 a 50 & 26,07 & 33,98 & 60,05 \\
Mais de 50 & 26,81 & 33,98 & 60,79 \\
Média & 20,43 & 32,98 & 42,50 \\
\hline
\end{tabular}

(1) INSS ou previdência pública e imposto de renda.

(2) INSS ou previdência pública, seguro de acidentes do trabalho, sistema "S" e salário-educação.

Fonte: Instituto Brasileiro de Planejamento Tributário (IBPT)

No Brasil, a dificuldade de controlar a evasão introduzida no sistema tributário através dos tributos convencionais declaratórios leva o governo a buscar fontes alternativas de mais fácil arrecadação, como o trabalho assalariado com carteira assinada. Por ser facilmente tributado, a incidência tributária sobre o mercado formal de trabalho no Brasil suporta uma carga de impostos que fica abaixo apenas da observada na Dinamarca, conforme mostra a Tabela 2. 
Tabela 2

Carga tributária sobre salário bruto em países selecionados

\begin{tabular}{|lc|}
\hline Países & Carga tributária sobre salário bruto (\%) \\
\hline Dinamarca & 42,9 \\
Brasil & 42,5 \\
Bélgica & 41,4 \\
Alemanha & 41,2 \\
Finlândia & 31,7 \\
Suécia & 31,2 \\
Noruega & 28,8 \\
Holanda & 28,7 \\
Uruguai & 28,4 \\
Itália & 28,1 \\
Argentina & 27,5 \\
Estados Unidos & 24,3 \\
Suíça & 21,5 \\
Espanha & 19,2 \\
Portugal & 16,5 \\
México & 9,1 \\
\hline
\end{tabular}

Fonte: IBPT

A maior parte do ônus sobre os salários se refere às contribuições econômicas e sociais incidentes sobre a folha de pagamentos das empresas. Há uma variação conforme a atividade (agropecuária, indústria, transporte, comércio e serviços), mas de um modo geral os tributos são: INSS (20\% para as empresas em geral e 22,5\% para as empresas financeiras), FGTS (8\%), Seguro de Acidentes do Trabalho (1\% 2\% ou 3\%, dependendo do grau de risco da atividade), Salário-Educação (2,5\%), Incra (0,2\% a 2,7\%), Sebrae $(0,3 \%$ a $0,6 \%)$, Senai/Senac (1\%), Sesi/Sesc $(1,5 \%)$ e outras contribuições $(0,2 \%$ a $2,5 \%)$. 
A proposta de desonerar a folha de pagamentos das empresas mediante a eliminação das contribuições patronais previdenciárias poderá ser forte fator indutor para a formalização de empregos, a inclusão dos não filiados à Previdência Social, e ao reduzir o custo do trabalho, poderá estimular a expansão do emprego. O fim do INSS patronal proporcionará redução de cerca de $60 \%$ no custo tributário trabalhista para as empresas.

Cumpre afirmar que o elevado custo da contratação de empregados tem um efeito danoso sobre o mercado de trabalho ao provocar a expansão da economia informal. Hoje, apenas metade da população economicamente ativa participa regularmente do sistema previdenciário brasileiro. ${ }^{1}$ Essa perda da base de extração de receita para o INSS combinada com desequilíbrios atuariais assume um peso cada vez mais significativo na explicação dos crescentes déficits previdenciários.

Ademais, a evolução do mundo globalizado e integrado, juntamente com a revolução nos meios de comunicação, transporte e financeirização, tem alterado profundamente as formas de produção mundiais, em que terceirização, outsourcing e trabalho autônomo crescem mais aceleradamente do que a relação de trabalho assalariada convencional. Dessa forma, a base de sustentação financeira do sistema previdenciário brasileiro, dependente da folha de salários das empresas, encolhe perigosamente, tornando-se uma base de financiamento frágil e instável. ${ }^{2}$

A Tabela 3 mostra a evolução da deterioração do saldo previdenciário. Os déficits tiveram início em 1998 e se expadiram ano após ano até dobrar de tamanho em relação ao PIB no período entre 2003 e 2007. Em 2008 ocorreu uma redução por conta da expansão no nível do emprego formal no país, deflagrado pelo crescimento da economia, mas em 2009 a previsão é que o saldo negativo atinja entre $1,4 \%$ e $1,5 \%$ do PIB.

\footnotetext{
${ }^{1}$ Segundo dados levantados pela Arthur Andersen, a soma dos encargos sociais no Brasil equivale a $60,24 \%$ da folha de pagamentos, enquanto a média de 15 países pesquisados, entre eles México, Alemanha, Canadá, China, Cingapura, Coreia do Sul, Hong Kong, Estados Unidos, Escócia e Indonésia, é de apenas 13,67\%.

${ }^{2}$ A reportagem "A survey of globalization and tax: the mistery of the vanishing taxpayer", publicada na revista The Economist, 29 jan. 2000, aponta para a crescente dificuldade em tributar os fatores de produção com mais mobilidade, como os rendimentos do capital, ao afirmar que "the harder it gets to tax mobile people and businesses, the bigger the burden that will have to be borne by the immobile". Este fato acaba levando os governos a hipertributarem os fatores com menor mobilidade, como o trabalho.
} 


\section{Tabela 3}

\section{Evolução do saldo previdenciário}

\begin{tabular}{|lcl|}
\hline Ano & $\begin{array}{c}\text { Saldo previdenciário } \\
(\mathrm{R} \$ 1000)(1)\end{array}$ & \% do PIB \\
\hline 1997 & 3.300 .707 & $0,4 \%$ \\
1998 & -7.433 .852 & $-0,8 \%$ \\
1999 & -9.412 .332 & $-0,9 \%$ \\
2000 & -10.071 .944 & $-0,9 \%$ \\
2001 & -12.836 .216 & $-1,0 \%$ \\
2002 & -16.998 .979 & $-1,2 \%$ \\
2003 & -26.404 .655 & $-1,6 \%$ \\
2004 & -31.985 .381 & $-1,6 \%$ \\
2005 & -37.576 .033 & $-1,7 \%$ \\
2006 & -42.065 .104 & $-1,8 \%$ \\
2007 & -44.881 .653 & $-1,7 \%$ \\
2008 & -36.206 .742 & $-1,2 \%$ \\
\hline
\end{tabular}

Fonte: Ministério da Previdência Social/Aeps Infologo

A adoção da movimentação financeira como alternativa para substituir a contribuição previdenciária incidente sobre a folha de pagamentos das empresas implica importantes vantagens: ${ }^{3}$

1. Desonera a folha de pagamentos das empresas, barateando os custos de produção, principalmente nos setores terciários, mais intensivos em mão de obra;

2. Estimula a demanda por trabalho assalariado, reduzindo a tendência de excessiva terceirização motivada por altos encargos trabalhistas;

3 Importante assinalar que a mera alteração nas fontes de financiamento do RGPS não resolveria o problema estrutural de seu desequilíbrio atuarial. Concomitantemente às alterações nas formas de financiamento, que poderiam ter impactos macroeconômicos positivos e consequentemente auxiliar no reequilíbrio do sistema, é fundamental que haja uma ampla discussão dos métodos e procedimentos relativos aos benefícios concedidos, tais como idade de aposentadoria, aposentadorias especiais, prazos de carência etc (Ver: Ministério da Previdência e da Assistência Social, 2002). 
3. Combate o desemprego ao baratear a contratação de mão de obra;

4. Estimula a formalização das relações trabalhistas, uma vez que a crescente proporção do trabalho informal compromete a qualidade das relações trabalhistas no Brasil;

5. Reduz os custos tributários incidentes sobre o trabalho, abrindo espaço para a redução dos custos de produção e contribuindo para o controle da inflação;

6. Aumenta a competitividade dos produtos brasileiros diante de seus concorrentes externos mediante a eliminação da contribuição patronal ao INSS (redução de custos de produção);

7. Permite desonerar as exportações, uma vez que ocorreria a substituição de um tributo não desonerável (o INSS patronal) por outro, cuja base, a movimentação financeira, possibilita a desoneração total. As exportações seriam favorecidas e os produtos nacionais encontrariam condições mais justas de concorrência com a produção importada. ${ }^{4}$

8. Cria um modelo de financiamento que proporciona receitas mais estáveis ao INSS, uma vez que a base de movimentação financeira é menos volátil que a massa salarial. A renda e o emprego são variáveis vulneráveis às oscilações da atividade econômica.

\section{Regime previdenciário e bases de incidência}

O desestímulo ao uso dos métodos de trabalhos intensivos de produção bem como a precarização das relações de trabalho no Brasil são fenômenos preocupantes, principalmente em uma economia como a brasileira, que conta com abundância relativa de mão de obra e com graves problemas de atendimento social e de qualidade de vida essencialmente para a população de mais baixa renda. ${ }^{5}$ Nesse sentido, o deslocamento do fato gerador das receitas previden-

\footnotetext{
${ }^{4}$ A desoneração é possível através de rebates fiscais calculados com a utilização da matriz interindustrial produzida pelo IBGE. Quanto às importações, alguns produtos poderiam ser onerados nos mesmos níveis dos similares nacionais.

5 Segundo o Ministério da Previdência e Assistência Social (2002:61-62), os encargos sobre a folha de salários no Brasil são superiores aos da maior parte dos países em nível equivalente de desenvolvimento, e semelhantes aos dos países da OCDE. Isso explica, em parte, o fato de mais de 40 milhões de trabalhadores não contarem com nenhuma cobertura previdenciária. Em sua
} 
ciárias da base salarial para outras, como o faturamento, o valor agregado ou a movimentação financeira, vem recebendo crescente atenção por parte dos pesquisadores e especialistas nessa questão. Trata-se de uma forma de estimular a inclusão no sistema previdenciário dos trabalhadores refugiados na economia informal.

Preliminarmente cabe analisar as alternativas de financiamento do regime geral de previdência dentro de uma árvore de decisões que justificaria conceitualmente uma ou outra opção.

O Gráfico 1 situa as diferentes opções de financiamento. Ao final de cada trajetória de opções surgirão as formas de financiamento que mais adequadamente se enquadram em cada situação.

A primeira decisão é saber se a previdência social deve ser obrigatória ou opcional. A literatura e a experiência acumulada indicam que o sistema deve ser obrigatório, pelo menos até o limite de renda que possa garantir uma sobrevivência minimamente aceitável para os trabalhadores que venham a perder sua capacidade laboral, principalmente por idade, mas também por outras causas socialmente justificadas. Se o enquadramento fosse opcional, o conceito a presidir sua formação seria o de capitalização individual, podendo os custos do sistema serem totalmente suportados pelo beneficiário-empregado, ou eventualmente negociados para haver um sistema compartilhado de financiamento entre o empregado e o empregador. A opção teria como consequência lógica um regime de financiamento incidente sobre folha de salário, mediante desconto de parte do rendimento do empregado, e outra parte como um salário indireto e diferido, a ser suportado pelo empregador.

A segunda decisão, é definir se o sistema obrigatório, provavelmente com tetos de contribuição e de benefício, seria estruturado pelo conceito de repartição (ou caixa) ou de capitalização (contas individuais com contribuição definida e benefício variável).

A filosofia previdenciária induz inicialmente à aceitação do princípio da capitalização, como se o sistema implicasse um seguro contra a perda

participação nos seminários realizados na Câmara dos Deputados (vide N.R.2), o então diretor de Arrecadação do INSS afirmou ser aspecto importante "a redução do número de trabalhadores com carteira assinada que migram para setores da economia informal. As estatísticas mostram que dois terços deles não recebem qualquer tipo de proteção. Temos tentado incessantemente identificá-los, buscando oferecer-lhes a proteção previdenciária que, em algum momento, será necessária. Se não nos preocuparmos com esse aspecto agora, no futuro teremos de oferecer assistência social sem qualquer contrapartida ao sistema" (p. 55). 
de capacidade laboral. Em geral, os sistemas previdenciários tiveram início como regimes de capitalização, ou seja, incorporando a filosofia do seguro com plena correspondência entre benefícios e o valor da capitalização em nome de cada indivíduo. As caixas de previdência no Brasil tiveram essa origem.

Não sendo o objetivo deste trabalho analisar a evolução histórica do sistema previdenciário brasileiro, bastaria apontar que os estudos e as projeções efetuadas pelo governo e por especialistas mostram que o sistema evoluiu (ou involuiu) para um regime de caixa, e o custo de transição para o sistema de capitalização seria no momento proibitivo, estimado em até 100\% do PIB, principalmente para o governo em seus três níveis. Nesse sentido, a opção possível é a continuidade do regime de repartição, com a possibilidade de complementação voluntária para benefícios superiores ao teto do sistema público obrigatório.

Além dessa razão pragmática pela continuidade do sistema de caixa, cumpre reconhecer que nas sociedades modernas o conceito de uma rede social de segurança para todos os cidadãos concede ao sistema uma conotação de política pública, devendo o governo arcar com as despesas resultantes do sistema, mesmo que ele se revele deficitário em termos de seus mecanismos de financiamento. Trata-se de uma opção das sociedades modernas no sentido de garantir, como direito de todos os cidadãos, os benefícios da previdência até o teto legal. ${ }^{6}$ Nessa conceituação, o financiamento do sistema pode contar não apenas com contribuições, mas também com impostos, como mecanismos de financiamento. A característica assistencial que o sistema assume justifica o descolamento entre as fontes de custeio e os seus respectivos beneficiários. A Constituição de 1988 incorporou essa conceituação ao definir, conforme o caput do artigo 195, que o custeio do sistema previdenciário compete a "toda sociedade, de forma direta e indireta". Nesse sentido, o regime geral de previdência brasileiro se afasta do conceito de seguro individual, para assumir uma conotação de política pública de renda complementar.

\footnotetext{
${ }^{6}$ Silva e Melo (1999) apontam que o sistema de capitalização não pode ser visto como solução única ou como panaceia: "A solução baseada na capitalização individual se inscreve numa tradição histórica de sistema de proteção de tipo residualista, onde as questões redistributivas e de integração social não são enfatizadas. Os modelos solidário-universalistas são mais inclusivos, mas à luz das transformações recentes dos mercados de trabalho e da transição demográfica exigem inovações importantes para que se tornem sustentáveis".
} 


\section{Gráfico 1}

Conceitos previdenciários e base de incidência

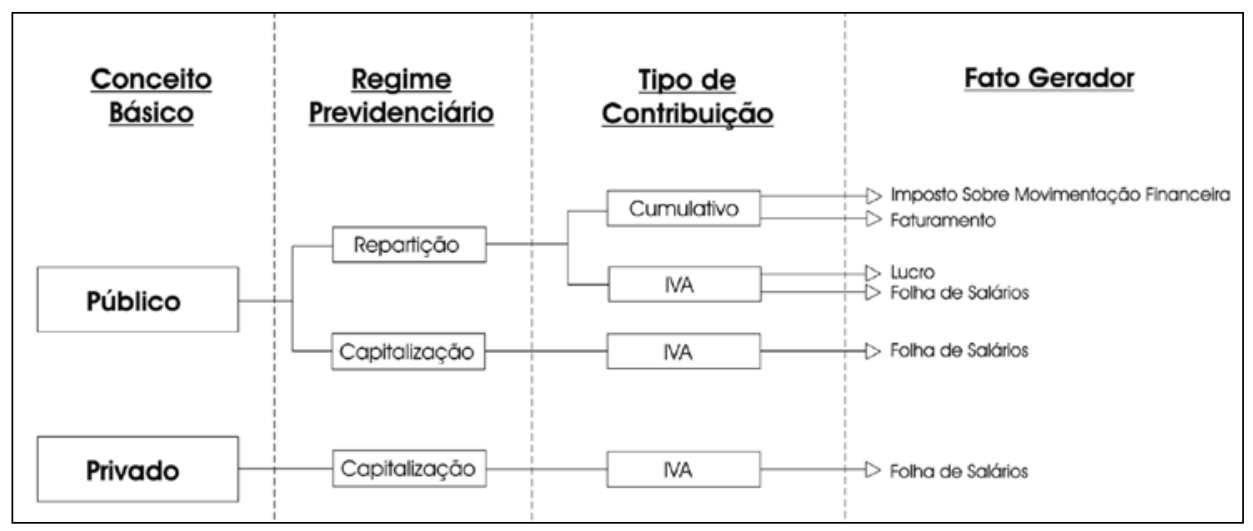

Se a opção fosse o regime de seguro ou de capitalização, o mecanismo de financiamento apropriado seria a incidência sobre folha de salários, arcada pelos beneficiários empregados e pelos empregadores. Não havendo essa opção, surgem duas alternativas: deve o financiamento do sistema ser feito por incidências do tipo IVA (valor agregado) ou por tributos do tipo turnover (cumulativos)?

$\mathrm{Na}$ categoria dos IVAs poderiam ser mencionadas as incidências sobre folha de salários, sobre lucro ou sobre faturamento, desde que fossem permitidos os créditos gerados nas etapas anteriores do processo produtivo, se for o caso. Cumpre notar que a incidência atual sobre folha de salários é uma forma específica de contribuição sobre valor agregado, ainda que não seja necessário o reconhecimento de créditos anteriores, pela sua inexistência. O mesmo se aplicará à tributação do lucro das empresas.

O presente trabalho vai se ater às possibilidades abertas nessa árvore de decisão deste ponto em diante. Será demonstrada a inconveniência de imposição de novos tributos sobre valor agregado, pois se trata de uma base já exaustivamente explorada no sistema tributário brasileiro, sendo inconveniente que sobre ela se imponham novas demandas.

Em seguida, será defendida, entre os tributos cumulativos, a opção de financiamento da previdência mediante uma contribuição sobre movimentação financeira, descartando-se a opção cumulativa incidente sobre bases declaratórias, do tipo faturamento. Tentar-se-á demonstrar que o financiamento do INSS mediante a aplicação de um tributo sobre a movimentação financeira será capaz de garantir a arrecadação necessária, e ao mesmo tempo reduzir a cunha tributária sobre salários, estimulando a formalização dos contratos tra- 
balhistas e a abertura de novos postos de trabalho, combatendo a sonegação e reduzindo custos tributários e o custo Brasil.

Serão apresentadas simulações que visam avaliar o impacto na carga tributária setorial de uma contribuição sobre movimentação financeira para substituir os $20 \%$ sobre a folha de salários destinados ao INSS. Estima-se que o impacto na formação de preços da economia abrirá amplo espaço para redução de preços e/ou ampliação de salários nominais e de margens de lucro. Utilizou-se, para o cálculo da alíquota necessária, a experiência arrecadatória da Contribuição Provisória Sobre Movimentação Financeira (CPMF), prevendo-se uma arrecadação equivalente à atual contribuição das empresas para a Previdência Social.

Finalmente, será avaliada a questão da cumulatividade da tributação sobre movimentação financeira, uma das principais críticas dos defensores dos IVAs.

\section{Imposto sobre Valor Agregado (IVA) versus Imposto sobre Movimentação Financeira (IMF)}

Desde os primeiros trabalhos sobre o Imposto Único sobre Transação (um IMF), ${ }^{7}$ tentou-se avaliar o impacto dos impostos cumulativos na formação dos preços na economia. Foram utilizadas as matrizes de relações interindustriais do IBGE e suas atualizações, tendo-se chegado à conclusão de que, por exigirem alíquotas nominais sensivelmente mais baixas do que os IVAs, e consequentemente, por desestimularem a sonegação, os IMFs impactariam com menor intensidade os preços na economia em comparação com a situação limite de ausência de tributação.

A cumulatividade, ou o efeito "cascata", levou erroneamente alguns críticos a acreditar que as cadeias de produção "longas" poderiam potencializar o impacto altista nos custos de produção. As simulações efetuadas então mostraram o equívoco dessas afirmações.

Sabidamente, todos os impostos introduzem distorções nos preços relativos. Contudo, passou-se a acreditar que o efeito cumulativo dos IMFs poderia causar alterações mais intensas. Acreditava-se que os IVAs seriam menos distorcivos, já que a carga tributária na composição final dos preços teoricamente poderia ser controlada pelo formulador da política econômica. O que esses

\footnotetext{
${ }^{7}$ Ver principalmente Cintra (1994:203-245).
} 
argumentos deixaram de considerar é que a evasão é um fato marcante da realidade tributária brasileira, e que os IVAs estimulam a sonegação a partir de suas altas alíquotas, e consequentemente podem afetar os preços relativos de forma mais intensa e aleatória que os IMFs.

A hipótese acerca da superioridade dos IVAs relativamente aos tributos cumulativos seria parcialmente verdadeira se duas condições fossem satisfeitas. A primeira é a ausência de sonegação; e a segunda, a existência de alíquotas uniformes por todos os setores e produtos. Como sabidamente nenhuma dessas duas hipóteses é verdadeira, a conclusão de que os IVAs introduzem menos distorções do que os IMFs não pode ser feita $a$ priori.

Ademais, os impactos nos preços relativos dependem não apenas do tipo de tributo, mas também da intensidade de seu uso, ou seja, de suas respectivas alíquotas. Como para um dado nível de receita os IMFs necessitam de alíquotas significativamente mais baixas do que os IVAs, percebe-se imediatamente a fragilidade das afirmações de que os tributos cumulativos necessariamente introduzem distorções mais fortes nos preços relativos.

A presença de alíquotas diferenciadas e a existência de sonegação significativamente mais elevada nos IVAs fazem com que os impactos nos preços da economia sejam tão não controláveis, aleatórios e não intencionais quanto no caso de IMFs.

Possivelmente as distorções geradas pelos IVAs sejam até mais fortes do que nos IMFs, já que a sonegação é fenômeno intensamente volátil, mutável, imprevisível e camuflado. Nos IMFs, a variabilidade de seus impactos nos custos de produção setoriais decorrem de alterações nas funções de produção, que ocorrem apenas no médio e no longo prazo. Isto faz com que os IMFs, mesmo tendo padrões de incidência não intencionais e não controláveis, possuam mais estabilidade do que os IVAs. A sonegação é geralmente instável mesmo a curtíssimo prazo, tornando os efeitos alocativos dos IVAs ainda mais mutáveis e imprevisíveis do que nos IMFs.

\section{Comparativo dos impactos setoriais de uma Contribuição sobre Movimentação Financeira (CMF) com a atual contribuição patronal ao INSS}

Neste estudo compara-se o impacto nos preços setoriais do INSS sobre a folha de pagamentos das empresas (que é um tipo de IVA) com um IMF, aqui denominado de Contribuição sobre Movimentação Financeira (CMF). Esse exercício foi elaborado visando averiguar a tese de que tributos sobre valor 
agregado são necessariamente preferíveis relativamente aos cumulativos no tocante aos efeitos sobre os preços relativos e sobre a carga tributária.

A simulação apresentada a seguir tentará mostrar que, mesmo supondose sonegação zero de INSS patronal, o que é uma evidente inverdade, a CMF, por ter alíquota mais baixa, implicará menor distorção nos preços relativos do que a contribuição sobre salários.

Trata-se de um exercício de estática comparativa, onde o modelo tributário da CMF (cumulativa) e da incidência sobre folha de pagamentos (um caso particular de valor agregado) serão comparados com uma situação heurística de ausência de tributação, que supostamente deveria ser o preço de equilíbrio competitivo. Nesse sentido, quanto mais os preços setoriais se distanciarem dos preços livres de tributos (que no modelo foram igualados à unidade), maior o impacto distorcivo que demonstram ter na formação das cargas tributárias setoriais.

A seguir, será montada a matriz dos preços relativos setoriais, e a distância de cada preço relativo do valor unitário estará medindo a distorção causada pelo respectivo modelo tributário no preço relativo daquele determinado par de setores. ${ }^{8}$ A medida de distorção global é dada pelo desvio padrão dos preços relativos da matriz em relação à unidade.

A simulação compara o impacto nos preços relativos de 110 produtos com uma CMF sendo usada como a fonte de financiamento do INSS relativamente a um modelo tributário convencional com a alíquota básica de $20 \%$ da contribuição patronal sobre folha de salários. ${ }^{9}$ A metodologia adotada utiliza a matriz de Leontief e dados das contas nacionais elaborados pelo IBGE para 2006, a mais recente série disponível até a data deste texto.

As equações fundamentais do modelo estão expostas no livro Bank transactions: pathway to the single tax ideal, recentemente lançado nos Estados Unidos. São realizadas simulações comparando modelos com IVAs e com um IMF. ${ }^{10}$ As equações fundamentais de formação dos preços nos modelos são dadas por:

$$
\begin{aligned}
& P_{i}=(1+t)\left\{(1+t)\left[\sum_{j}\left(b_{i j} P_{j}\right)+w_{i}\right]\left(1+m_{i}\right)\right\} \text { para o IMF, e } \\
& P_{i}=(1 /(1-v))\left\{\left[\left(\sum_{j}\left(b_{i j} P_{j}\right)+w_{i}\right)\left(1+m_{i}\right)\right]-v \sum_{j}\left(b_{i j} P_{j}\right)\right\} \text { para um IVA, onde: }
\end{aligned}
$$

\footnotetext{
${ }^{8}$ Maiores detalhes sobre o modelo utilizado poderão ser obtidos em Cintra (2003 e 2009).

${ }^{9} \mathrm{O}$ ideal nesse tipo de simulação seria o uso de modelos de equilíbrio geral, já que os mesmos captariam os efeitos dinâmicos das alterações tributárias. Sobre o uso de modelos de equilíbrio geral computáveis, ver Domingues e Haddad (2003), onde o modelo é usado para simulações regionais para o estado de São Paulo. Trata-se de campo fértil para pesquisa futura.

${ }^{10}$ Os detalhes para a obtenção das equações estão disponíveis no capítulo 2 de Cintra (2009).
} 
$\mathrm{P}_{\mathrm{i}}=$ Preço do produto $\mathrm{i}$

$\mathrm{b}_{\mathrm{ij}}=$ Valor do insumo $\mathrm{j}$ por unidade do valor do produto $\mathrm{i}$

$\mathrm{P}_{\mathrm{j}}=$ Preço do produto $\mathrm{j}$

$\underline{\mathrm{w}}_{\mathrm{i}}=$ Valor do insumo trabalho por unidade de valor do produto $\mathrm{i}$

$\mathrm{m}_{\mathrm{i}}=$ Mark-up sobre custos na produção do produto i

$\mathrm{t}=$ Alíquota do Imposto sobre Movimentação Financeira (IMF)

$\mathrm{v}=$ Alíquota do Imposto sobre Valor Agregado (IVA).

Para a simulação dos impactos da CMF como substituta do INSS das empresas foi necessário estimar qual seria sua alíquota para substituir toda a arrecadação referente à contribuição patronal sobre a folha de pagamentos. A aplicação de $0,61 \%$ sobre as movimentações financeiras seria suficiente para cobrir os R $\$ 63,4$ bilhões recolhidos a título de contribuição de empresas em 2008, conforme mostra a Tabela 4.

A alíquota de $0,61 \%$ foi obtida utilizando como referência a arrecadação da CPMF com alíquota de 0,38\%, que vigorou entre 2002 e 2007. A base média de sua cobrança foi equivalente nesses seis anos a 3,6 vezes o PIB brasileiro e para 2008 manteve-se essa mesma ordem de grandeza, o que gerou um montante estimado de $\mathrm{R} \$ 10,5$ trilhões. Resumindo: uma CMF com alíquota de $0,61 \%$ sobre as movimentações financeiras geraria uma arrecadação para o INSS equivalente aos $20 \%$ patronais sobre folha (40\% da arrecadação total do INSS).

Tabela 4

Receitas de contribuições ao INSS em 2008 (R\$ 1.000)

\begin{tabular}{|lr|}
\hline Receitas de contribuições & \multicolumn{1}{c|}{2008} \\
\hline Contribuição de segurados & 31.923 .541 \\
Contribuição de empresas & 63.380 .876 \\
Contribuição individual de segurados & 2.661 .638 \\
Contribuição do segurado facultativo & 640.903 \\
Contribuição do empregado doméstico & 1.832 .142 \\
Contribuição do segurado especial & 5.661 \\
Contribuição de espetáculos esportivos & 43.132 \\
Seguro de acidente do trabalho urbano & 7.417 .118 \\
Parcelamento de débito & 1.989 .967 \\
Contribuição sobre a produção rural & 2.480 .292 \\
Simples & 10.467 .492 \\
Previdência dos órgãos do setor público & 13.848 .649 \\
Certificado Fies & 672.277 \\
\hline
\end{tabular}




\begin{tabular}{|lc|}
\hline Receitas de contribuições & \multicolumn{1}{c|}{2008} \\
\hline Depósitos judiciais & 1.423 .546 \\
Programa de recuperação fiscal & 2.979 .466 \\
Contribuição de entidades filantrópicas & 1.577 .169 \\
Retenção sobre nota fiscal & 13.038 .867 \\
Reclamatória trabalhista & 1.522 .427 \\
Restituições & -640.971 \\
Total & 157.264 .192 \\
\hline
\end{tabular}

Fonte: Anuário estatístico da Previdência Social - 2008

No resultado da simulação, apresentado na Tabela 5, vê-se que a carga tributária setorial imposta pela CMF sofreria significativa diminuição comparativamente ao atual modelo de financiamento.

Vê-se que o desvio nos preços relativos (última linha da tabela) foi de 0,33\% no caso da CMF, e de $1,65 \%$ no caso do atual modelo de financiamento do INSS. Comprova-se assim a inveracidade da afirmação de que necessariamente os tributos cumulativos geram maiores distorções nos preços relativos. Não se pode afirmar a priori que isto ocorra ou deixe de ocorrer. Contudo, pode-se afirmar que nas circunstâncias da economia brasileira a crítica não se revelou verdadeira.

Outro resultado importante é a redução significativa da carga tributária setorial resultante da alteração nas fontes de financiamento do INSS. Enquanto no caso convencional houve uma variação entre $8,93 \%$ e $15,37 \%$, com a CMF ela caiu significativamente para entre 1,09\% e 2,39\%.

Tabela 5

Simulação do impacto da CMF e do INSS nos preços setoriais

\begin{tabular}{|cllcc|}
\hline & & \multicolumn{2}{c|}{$\begin{array}{c}\text { Carga tributária \% sobre o } \\
\text { faturamento }\end{array}$} \\
\cline { 3 - 4 } & Produtos & CMF 0,61\% & INSS 20\% \\
\hline 1 & Arroz em casca & 1,85 & 14,21 \\
2 & Milho em grão & 1,71 & 14,71 \\
3 & Trigo em grão e outros cereais & 1,89 & 13,65 \\
4 & Cana-de-açúcar & 1,94 & 13,99 \\
5 & Soja em grão & 1,87 & 14,13 \\
6 & Outros produtos e serviços da lavoura & 1,63 & 14,61 \\
\hline
\end{tabular}




\begin{tabular}{|c|c|c|c|}
\hline & \multirow[b]{2}{*}{ Produtos } & \multicolumn{2}{|c|}{$\begin{array}{c}\text { Carga tributária \% sobre o } \\
\text { faturamento }\end{array}$} \\
\hline & & CMF $0,61 \%$ & INSS $20 \%$ \\
\hline 7 & Mandioca & 1,70 & 14,54 \\
\hline 8 & Fumo em folha & 1,92 & 13,94 \\
\hline 9 & Algodão herbáceo & 1,83 & 14,26 \\
\hline 10 & Frutas cítricas & 1,90 & 14,09 \\
\hline 11 & Café em grão & 1,91 & 14,08 \\
\hline 12 & Produtos da exploração florestal e da silvicultura & 1,67 & 13,85 \\
\hline 13 & Bovinos e outros animais vivos & 2,02 & 14,86 \\
\hline 14 & Leite de vaca e de outros animais & 2,03 & 14,77 \\
\hline 15 & Suínos vivos & 2,06 & 14,82 \\
\hline 16 & Aves vivas & 2,04 & 14,91 \\
\hline 17 & Ovos de galinha e de outras aves & 1,69 & 15,30 \\
\hline 18 & Pesca e aquicultura & 2,01 & 14,94 \\
\hline 19 & Petróleo e gás natural & 1,71 & 10,65 \\
\hline 20 & Minério de ferro & 2,10 & 14,20 \\
\hline 21 & Carvão mineral & 1,93 & 12,36 \\
\hline 22 & Minerais metálicos não ferrosos & 1,88 & 12,09 \\
\hline 23 & Minerais não metálicos & 1,81 & 12,89 \\
\hline 24 & Abate e preparação de produtos de carne & 1,98 & 14,99 \\
\hline 25 & Carne de suíno fresca, refrigerada ou congelada & 2,06 & 14,89 \\
\hline 26 & Carne de aves fresca, refrigerada ou congelada & 1,94 & 15,06 \\
\hline 27 & Pescado industrializado & 2,07 & 14,88 \\
\hline 28 & Conservas de frutas, legumes e outros vegetais & 2,16 & 14,71 \\
\hline 29 & Óleo de soja em bruto e tortas, bagaços e farelo de soja & 2,28 & 14,65 \\
\hline 30 & Outros óleos e gordura vegetal e animal exclusive milho & 2,14 & 14,75 \\
\hline 31 & Óleo de soja refinado & 2,02 & 14,97 \\
\hline 32 & Leite resfriado, esterilizado e pasteurizado & 2,04 & 14,95 \\
\hline 33 & Produtos do laticínio e sorvetes & 1,92 & 15,08 \\
\hline 34 & Arroz beneficiado e produtos derivados & 1,78 & 15,20 \\
\hline 35 & Farinha de trigo e derivados & 2,21 & 14,72 \\
\hline
\end{tabular}

Continua 


\begin{tabular}{|c|c|c|c|}
\hline & \multirow[b]{2}{*}{ Produtos } & \multicolumn{2}{|c|}{$\begin{array}{l}\text { Carga tributária \% sobre o } \\
\text { faturamento }\end{array}$} \\
\hline & & CMF $0,61 \%$ & INSS $20 \%$ \\
\hline 36 & Farinha de mandioca e outros & 1,81 & 14,94 \\
\hline 37 & Óleos de milho, amidos e féculas vegetais e rações & 1,98 & 14,97 \\
\hline 38 & Produtos das usinas e do refino de açúcar & 2,19 & 14,75 \\
\hline 39 & Café torrado e moído & 1,95 & 15,04 \\
\hline 40 & Café solúvel & 2,14 & 14,82 \\
\hline 41 & Outros produtos alimentares & 1,94 & 15,05 \\
\hline 42 & Bebidas & 2,11 & 14,71 \\
\hline 43 & Produtos do fumo & 2,19 & 14,16 \\
\hline 44 & Beneficiamento de algodão e de outros têxteis e fiação & 1,83 & 13,72 \\
\hline 45 & Tecelagem & 1,72 & 14,01 \\
\hline 46 & Fabricação de outros produtos têxteis & 1,77 & 14,01 \\
\hline 47 & Artigos do vestuário e acessórios & 1,61 & 15,08 \\
\hline 48 & $\begin{array}{l}\text { Preparação do couro e fabricação de artefatos - exclusive } \\
\text { calçados }\end{array}$ & 1,83 & 14,56 \\
\hline 49 & Fabricação de calçados & 1,80 & 14,80 \\
\hline 50 & Produtos de madeira - exclusive móveis & 1,89 & 14,62 \\
\hline 51 & Celulose e outras pastas para fabricação de papel & 1,94 & 14,17 \\
\hline 52 & Papel e papelão, embalagens e artefatos & 1,76 & 13,79 \\
\hline 53 & Jornais, revistas, discos e outros produtos gravados & 1,55 & 14,66 \\
\hline 54 & Gás liquefeito de petróleo & 1,98 & 12,86 \\
\hline 55 & Gasolina automotiva & 2,39 & 11,46 \\
\hline 56 & Gasoálcool & 1,92 & 12,90 \\
\hline 57 & Óleo combustível & 2,18 & 11,99 \\
\hline 58 & Óleo diesel & 2,00 & 12,00 \\
\hline 59 & Outros produtos do refino de petróleo e coque & 1,95 & 10,91 \\
\hline 60 & Álcool & 2,07 & 14,64 \\
\hline 61 & Produtos químicos inorgânicos & 1,68 & 11,50 \\
\hline 62 & Produtos químicos orgânicos & 1,58 & 9,36 \\
\hline 63 & Fabricação de resina e elastômeros & 1,60 & 9,94 \\
\hline 64 & Produtos farmacêuticos & 1,37 & 14,25 \\
\hline
\end{tabular}




\begin{tabular}{|c|c|c|c|}
\hline & \multirow[b]{2}{*}{ Produtos } & \multicolumn{2}{|c|}{$\begin{array}{l}\text { Carga tributária \% sobre o } \\
\text { faturamento }\end{array}$} \\
\hline & & CMF $0,61 \%$ & INSS $20 \%$ \\
\hline 65 & Defensivos agrícolas & 1,79 & 13,25 \\
\hline 66 & Perfumaria, sabões e artigos de limpeza & 1,78 & 13,82 \\
\hline 67 & Tintas, vernizes, esmaltes e lacas & 1,78 & 13,50 \\
\hline 68 & Produtos e preparados químicos diversos & 1,67 & 12,00 \\
\hline 69 & Artigos de borracha & 1,79 & 12,17 \\
\hline 70 & Artigos de plástico & 1,74 & 12,19 \\
\hline 71 & Cimento & 1,93 & 14,20 \\
\hline 72 & Outros produtos de minerais não metálicos & 1,86 & 13,84 \\
\hline 73 & Gusa e ferro-ligas & 2,04 & 13,94 \\
\hline 74 & Semiacabados, laminados planos, longos e tubos de aço & 1,88 & 13,00 \\
\hline 75 & Produtos da metalurgia de metais não ferrosos & 1,90 & 12,22 \\
\hline 76 & Fundidos de aço & 2,11 & 13,48 \\
\hline 77 & Produtos de metal - exclusive máquinas e equipamentos & 1,79 & 12,95 \\
\hline 78 & Máquinas e equipamentos, inclusive manutenção e reparos & 1,76 & 11,62 \\
\hline 79 & Eletrodomésticos & 1,83 & 13,98 \\
\hline 80 & Máquinas para escritório e equipamentos de informática & 1,71 & 11,91 \\
\hline 81 & Máquinas, aparelhos e materiais elétricos & 1,74 & 11,77 \\
\hline 82 & Material eletrônico e equipamentos de comunicações & 1,47 & 8,93 \\
\hline 83 & $\begin{array}{l}\text { Aparelhos/instrumentos médico-hospitalares, medida e } \\
\text { óptico }\end{array}$ & 1,44 & 13,30 \\
\hline 84 & Automóveis, camionetas e utilitários & 2,06 & 13,10 \\
\hline 85 & Caminhões e ônibus & 1,96 & 13,36 \\
\hline 86 & Peças e acessórios para veículos automotores & 1,71 & 11,73 \\
\hline 87 & Outros equipamentos de transporte & 1,81 & 12,69 \\
\hline 88 & Móveis e produtos das indústrias diversas & 1,53 & 14,86 \\
\hline 89 & Sucatas recicladas & 2,03 & 13,93 \\
\hline 90 & Eletricidade e gás, água, esgoto e limpeza urbana & 1,55 & 14,13 \\
\hline 91 & Construção & 1,71 & 14,72 \\
\hline 92 & Comércio & 1,36 & 14,59 \\
\hline 93 & Transporte de carga & 1,78 & 14,42 \\
\hline
\end{tabular}




\begin{tabular}{|llcc|}
\hline & & \multicolumn{2}{c|}{$\begin{array}{c}\text { Carga tributária } \% \text { sobre o } \\
\text { faturamento }\end{array}$} \\
\cline { 3 - 4 } & Produtos & CMF $0,61 \%$ & INSS $20 \%$ \\
\hline 94 & Transporte de passageiro & 1,58 & 14,30 \\
95 & Correio & 1,69 & 14,49 \\
96 & Serviços de informação & 1,40 & 14,33 \\
97 & Intermediação financeira e seguros & 1,33 & 15,05 \\
98 & Serviços imobiliários e aluguel & 1,09 & 13,52 \\
99 & Aluguel imputado & 2,14 & 14,11 \\
100 & Serviços de manutenção e reparação & 1,39 & 14,85 \\
101 & Serviços de alojamento e alimentação & 1,62 & 15,18 \\
102 & Serviços prestados às empresas & 1,29 & 12,96 \\
103 & Educação mercantil & 1,32 & 15,37 \\
104 & Saúde mercantil & 2,11 & 13,69 \\
105 & Serviços prestados às famílias & 1,42 & 15,32 \\
106 & Serviços associativos & 1,59 & 15,05 \\
107 & Serviços domésticos & 2,17 & 14,06 \\
108 & Educação pública & 2,39 & 14,22 \\
109 & Saúde pública & 2,14 & 13,77 \\
110 & Serviço público e seguridade social & 2,03 & 14,28 \\
Carga tributária máxima & 2,03 & 15,37 \\
Medida dributária mínima & $2,65 \%$ \\
\hline
\end{tabular}

A simulação dos impactos sobre os preços confirma que a alteração proposta de substituição do INSS patronal pela CMF abrirá amplo espaço para a redução de preços e consequentemente para a ampliação dos salários reais e das margens de contribuição das empresas. Ademais, criam-se possibilidades para aumentos nominais de salários, sem impactos negativos na eficiência alocativa da economia.

Com essas observações esperamos avançar no entendimento da derradeira questão ainda pendente no debate a respeito de impostos sobre movimentação financeira: a de que não se pode afirmar a priori se a cumulatividade introduz maior distorção nos preços relativos de uma economia. No 
caso concreto da economia brasileira, o IMF não apenas implica menor carga tributária setorial como ainda introduz menos distorções nos preços relativos, do que resulta a conclusão de ser um tributo mais eficiente do que a atual incidência do INSS sobre folha de pagamentos das empresas.

\section{A questão da cumulatividade"1}

A cumulatividade, ou incidência em cascata, é a principal crítica feita pelos defensores do IVA quando avaliam tributos sobre movimentação financeira como a CMF. Certa vez, Roberto Campos se referiu à intrigante distinção feita pelos meios empresariais brasileiros entre dois tipos de cascata. Uma, tida como maligna, incluía a extinta CPMF e parte do atual PIS/Cofins. Contra eles são disparadas todas as críticas, justas ou injustas.

Por outro lado, existem tributos que são unanimemente aplaudidos pelos empresários, e tidos como elogiáveis contribuições que o Brasil oferece à ciência tributária. São eles o Simples e a tributação pela modalidade do lucro presumido. Cumpre observar que nesses dois casos a opção é exclusivamente das empresas, e que ao fazer essa escolha estão reduzindo suas obrigações tributárias. Merecem, portanto, rasgados elogios das lideranças empresariais, ainda que do ponto de vista estritamente técnico ambos sejam impostos em cascata tanto quanto era a CPMF ou o PIS/Cofins cumulativo.

\footnotetext{
${ }^{11}$ Diz-se que é cumulativo o tributo que incide em duas ou mais etapas da circulação de mercadorias sobre um mesmo fato gerador, sem que na etapa posterior possa ser abatido o montante pago na etapa anterior. O tributo é não cumulativo quando o montante do tributo pago numa etapa da circulação da mercadoria pode ser abatido do montante devido na etapa seguinte para o mesmo fato gerador. Everardo Maciel caracteriza a cumulatividade como "sistemas tributários cuja incidência não têm repercussão nem para frente nem para trás [...] O sistema de valor agregado [...] leva em consideração as informações para trás e para frente, tem um sistema de créditos e débitos. Qual é o melhor deles? Ambos têm virtudes e defeitos. No sistema cumulativo as alíquotas são menores. No valor agregado as alíquotas são maiores. Os sistemas cumulativos são muito mais simples. Os sistemas de valor agregado são mais complexos, prestam-se mais à evasão fiscal, à elisão [...] Os sistemas de valor agregado dão melhor quantificação contábil que os sistemas cumulativos.O equívoco é ser partidário de uma coisa ou de outra. Cada situação tem uma solução adequada. A generalização é um enorme equívoco. Portanto, a cumulatividade do sistema não constitui nenhum erro". Reforma Tributária e federalismo no Brasil, palestra proferida por Everardo Maciel na Federação das Indústrias de Brasília, 7 ago. 2001. Disponível em: <www.marcoscintra.org $>$.
} 
Vale notar que 93\% das empresas brasileiras optam pela tributação pelo lucro presumido ou pelo Simples. ${ }^{12}$ As empresas que adotam esses procedimentos simplificados de arrecadação nem sempre estão buscando reduzir suas respectivas cargas tributárias. Basta verificar que os critérios de aplicação do lucro presumido impõem uma alíquota efetiva para as empresas optantes (tributo sobre a receita bruta) entre $4,1 \%$ e $24 \%$, enquanto no lucro real, que abrange cerca de $6 \%$ das empresas, a alíquota efetiva é de apenas 1,3\%.

Cumpre dizer que mesmo os tributos tidos como não cumulativos apresentam várias formas de incidência cumulativa. Diz-se que um tributo ficaria mais perto da não cumulatividade pura se fosse admitido, por sua legislação, o chamado crédito financeiro. Nesse caso, o montante do tributo incidente sobre todas as mercadorias adquiridas (inclusive para o ativo permanente $\mathrm{e}$ para uso e consumo) pode ser aproveitado no pagamento do mesmo tributo devido pelo adquirente. O ICMS admite o aproveitamento do crédito relativo às aquisições destinadas ao ativo permanente, mas os créditos referentes aos bens de uso e consumo não são permitidos.

Há casos em que a incipiente estrutura administrativa do contribuinte impede o aproveitamento do crédito, tornando o imposto cumulativo. É o que ocorre, por exemplo, com os pequenos agricultores, adquirentes que são de equipamentos, sementes, fertilizantes e inseticidas tributados pelo ICMS. Como são incapazes de apresentar registros de suas operações de compra e venda, deixam de aproveitar o crédito relativo às entradas. Alguns estados dão permissão aos agricultores para o aproveitamento de créditos presumidos, mas, é claro, muitas vezes em valor inferior ao real.

No outro extremo estão os tributos que adotam a não cumulatividade parcial, pois admitem apenas o chamado crédito físico. Nesse caso, o aproveitamento se restringe ao montante do tributo incidente nas aquisições de bens que se destinam a integrar bens produzidos e comercializados ou só comercializados pelo adquirente. São, portanto, bens que entram para sair. É o caso do IPI, que impede, por exemplo, o industrial adquirente de aproveitar crédito do imposto sobre máquinas e equipamentos sujeitos ao imposto.

O próprio ICMS, tido como um imposto moderno por ser sobre valor agregado, carrega forte cumulatividade em sua operação. Quando a cadeia

\footnotetext{
${ }^{12}$ Ver: Secretaria da Receita Federal (2006). Em 2003, das 2.992 .041 empresas contribuintes do IRPJ, 1.978.727 optaram pelo Simples, 683.520 optaram pelo lucro presumido, e apenas 178.723 empresas eram tributadas pelo lucro real. Contudo, esta última categoria foi responsável por $80,8 \%$ da arrecadação.
} 
de débitos e créditos se rompe ele se torna cumulativo. Por exemplo, o setor agrícola em geral não encontra meios de se creditar do ICMS embutido no preço de seus insumos. Os prestadores de serviços são igualmente tributados pelo ICMS de forma totalmente cumulativa, já que, por não serem contribuintes desse tributo, não se creditam do valor recolhido nas etapas anteriores da produção. A recente tendência de arrecadar o ICMS mediante substituição tributária implica negação dos princípios basilares da tributação sobre valor agregado, o que comprova que na prática, os IVAs vêm sofrendo forte comprometimento de sua pureza conceitual.

Vê-se, portanto, a ambiguidade que envolve o debate dos tributos em cascata, já que até mesmo o maior imposto sobre valor agregado do país, o ICMS, vem se tornando cada dia mais cumulativo. ${ }^{13}$

Mas quais são as verdadeiras objeções à cumulatividade?

A objeção mais comum se refere ao impacto prejudicial da cumulatividade nos mercados financeiros e no comércio exterior.

Nada há que, tecnicamente, impeça o governo de desonerar as exportações e de onerar as importações em igualdade de condições com a produção nacional. Para isso basta adotar a matriz interindustrial calculada pelo IBGE como mecanismo de apuração do peso dos impostos sobre produtos. Conhecendo-se esse ônus, ele seria abatido no preço das exportações e acrescido no valor das importações.

Outra objeção diz respeito ao mercado financeiro, mas o governo mostrou ser possível resolver essa questão quando adotou medidas na época da CPMF para livrar o mercado financeiro do impacto do tributo. Em 2004, a conta-investimento isentou da cobrança da CPMF os recursos que permanecessem no circuito financeiro.

\footnotetext{
${ }^{13}$ Os críticos da cumulatividade são ágeis em apontar os malefícios causados pela incidência em cascata de parte do PIS/Cofins e da extinta CPMF, taxando-os de desastrosos para a eficiência e para a competitividade da produção nacional. Contudo, não atentam para os efeitos da cumulatividade implícita no Simples e no IPPJ-lucro presumido (que juntos abrangem 93\% da empresas brasileiras), no ISS, na cumulatividade parcial do IPVA e do IPTU, e nem mesmo para a crescente cumulatividade do ICMS e do IPI. Quando admitem que esta cumulatividade está presente na economia brasileira, dizem que a ocorrência se dá "em doses minúsculas, que não chegam a impor prejuízos significativos à produção" (Varsano et al, 2001). Vale apontar o impacto significativo do efeito cumulativo de importantes tributos como o ICMS e o IPI que, ao serem cobrados de setores não contribuintes desses impostos, como o setor primário e terciário (que compõem mais de $50 \%$ do PIB brasileiro) geram incidência totalmente em cascata na proporção de suas compras de insumos industriais.
} 
A experiência brasileira com a cumulatividade da extinta CPMF tem um mérito inegável: o de eliminar do atual sistema tributário sua maior aberração, qual seja, as diferenças artificiais de custos de produção causadas pela ampla e generalizada sonegação de impostos no país. A forma pela qual a evasão de impostos distribui a atual carga tributária implica distorção econômica mais grave do que a alegada alteração nos preços relativos que um turnover tax, como era a CPMF, poderia estar causando na economia brasileira. A CPMF atenuava essa grave distorção. Em geral, o custo da evasão acaba superando a própria economia tributária. Essa é a vantagem de um imposto não declaratório, que por ser insonegável permite alíquotas baixas, porém universais.

Esse tipo de tributação reduz custos, elimina a corrupção, distribui o ônus tributário na exata proporção das operações econômicas realizadas pelos contribuintes e, assim, os que pagam muito hoje, como os assalariados, poderão pagar menos, e os que sonegam, pagarão as suas partes.

O verdadeiro e o maior problema da estrutura tributária brasileira é, seguramente, a evasão de impostos, fonte de profundas distorções na economia do país (Cintra, 2001).

Uma análise racional exige que a avaliação de cada espécie tributária seja feita não apenas em termos de suas características intrínsecas, mas também considerando os padrões circunstanciais nos quais ela será aplicada.

Alega-se que o IVA possui a vantagem de introduzir menos alterações nos preços relativos do que os tributos cumulativos. Contudo, essa afirmação depende da aceitação da premissa da existência de mercados competitivos perfeitos. Sabe-se, contudo, que essa hipótese tem uma função essencialmente heurística, e que na prática os mercados não satisfazem os quesitos para serem considerados perfeitos. Nessas condições, a teoria do second best $t^{14}$ já demonstrou ser impossível fixar um ordenamento confiável de situações alternativas do mercado sem uma análise pontual e específica de cada cenário, o que evidentemente não é feito quando se afirma a priori que tributos sobre valor agregado são mais eficientes que os cumulativos.

Segundo os postulados da teoria do second best, como afirma J.A. Kay,

\footnotetext{
${ }^{14} \mathrm{O}$ teorema do second best prova que se uma das condições para a obtenção de um Ótimo de Pareto não for satisfeita, a melhor situação possível (o second best) em geral apenas poderá ser atingida com o relaxamento de todas as demais condições paretianas. Ver: Lipsey e Lancaster,(1956/57). Para uma abordagem avançada da teoria da tributação ótima, ver: Guesnerie (1998).
} 
Propostas de reformas tributárias não devem ser avaliadas contando-se o número de distorções, e argumentos baseados em "dupla tributação" ignoram o fato de que é o nível relativo da tributação, e não o número de vezes que o imposto incide, que é relevante na tomada de decisões econômicas. ${ }^{15}$

A moderna teoria do bem-estar demonstra que a sociedade não optará por uma situação alocativamente eficiente se, comparada a outra situação, mesmo que ineficiente, puder atingir um ponto superior em sua função de bem-estar social. ${ }^{16}$ Em outras palavras, mesmo que os IVAs introduzam menos distorções na formação dos preços relativos, é possível que impostos cumulativos sejam preferíveis se, por exemplo, puder ser comprovado que a sonegação é menor, ou que para uma mesma meta de arrecadação, sua alíquota nominal é mais baixa, do que resultaria um padrão de incidência tributária mais aceitável para a sociedade.

Outra situação semelhante poderia resultar da comparação entre os elevados custos de funcionamento dos IVAs relativamente aos impostos cumulativos, que por serem não declaratórios e arrecadados eletronicamente, implicam baixíssimos custos operacionais tanto para o setor público quanto para o privado.

Os IVAs introduzem distorções adicionais graves ao estimularem a excessiva terceirização, ao necessitarem de alíquotas elevadas para uma dada meta de arrecadação, e ao imporem elevadíssimos custos operacionais em sua implementação.

Os custos administrativos dos IVAs são elevados, especialmente em países federativos como o Brasil. São igualmente ineficientes, do ponto de vista operacional, quando aplicados por níveis subnacionais de governo. Os IVAs são tributos próprios de países unitários. Poucas nações federativas os aplicam, e as que o fazem, incorrem em elevados custos e em enormes complicações burocráticas, como o Brasil e o Canadá. ${ }^{17}$ Não é à toa que os Estados Unidos se mantiveram afastados dos IVAs. E não é por capricho que se busca

\footnotetext{
${ }^{15} \mathrm{O}$ autor de refere ao caso de dupla tributação no imposto de renda. Ver: Kay (1990).

${ }^{16}$ Para uma demonstração teórica deste ponto, ver: Cintra (2002). Cláudia e Ibrahim Eris (1983:31) mencionam que "é possível, se bem que improvável, que um plano fiscal menos eficiente seja preferível a um mais eficiente. A literatura de bem-estar está cheia de aparentes paradoxos e este parece ser mais um deles: a economia como um todo parece ter-se beneficiado mas os grupos que a compõem saíram prejudicados".

${ }^{17}$ Para uma eloquente descrição das dificuldades encontradas na aplicação de IVAs em países com organização federativa, ver: Bird e Gendron (2001).
} 
no Brasil a unificação do ICMS, após constatar-se sua absurda complexidade na forma como vem sendo aplicado.

No tocante aos efeitos alocativos do sistema tributário, cumpre observar que para minimizar distorções o ideal seria o uso de tributos que não causassem qualquer modificação nas decisões econômicas relativamente às que seriam tomadas em situação de ausência de impostos. Em outras palavras, um sistema tributário ideal minimizaria o dead-weight loss ("peso morto" dos impostos). Contudo, sabe-se que apenas um imposto sobre a vida, ou seja, um tributo de valor fixo per capita atingiria tal desiderato. Sendo, contudo, uma alternativa inaceitável nas sociedades modernas, resta a tentativa de minimizar perdas de eficiência. E nesse sentido, uma regra básica seria o uso de tributos capazes de mostrar altas alíquotas médias, porém baixas alíquotas marginais. Como as decisões econômicas são tomadas sempre na margem, o uso de tributos com essa característica seriam mais desejáveis que tributos que demonstrassem taxas médias e marginais constantes - como os IVAs - , ou então alíquotas marginais superiores às médias - como o imposto de renda progressivo (Eckstein, 1964:73).

Vê-se, assim que, ao necessitarem de alíquotas marginais mais baixas para uma dada meta de arrecadação, o tributo sobre movimentação financeira pode ser menos distorcivo do que os tributos sobre valor agregado, que exigem alíquotas marginais significativamente mais elevadas, desfazendo as certezas que cercam as afirmações sobre os males da cumulatividade e sobre os acertos dos tributos sobre valor agregado.

Vale apontar ainda que a sonegação e a elisão variam em proporção direta ao nível das alíquotas nominais dos impostos, ou seja, quanto mais altas as alíquotas, maior o estímulo e o prêmio à sonegação e à elisão. É fácil concluir, portanto, que os IVAs estimulam a sonegação e a evasão com maior intensidade do que os tributos que exigem alíquotas mais baixas, como os cumulativos. E à medida que a evasão e a sonegação aumentam, novas rodadas de aumentos de alíquotas tornam-se necessárias.

Assim, por terem alíquotas mais altas, e por estimularem a evasão, os IVAs possuem péssimos padrões de incidência. Alguns contribuintes pagam impostos em excesso, ao passo que muitos pagam pouco, ou menos do que deveriam. É o sistema do conluio contra o setor público, da venda sem nota, da venda com meia nota, dos passeios de notas fiscais e do "planejamento tributário". Criam-se, assim, distorções alocativas de grandes proporções, na medida em que os custos de produção e a capacidade de concorrência das empresas não mais definem sua eficiência de produção. Pelo contrário, a capacidade competitiva das empresas passa a depender, em grande parte, das taxas 
de evasão praticadas pelos administradores de empresas, relativamente a seus concorrentes. Estimula-se a sobrevivência dos espertos, a dominação dos mais corruptos, e a seleção do mercado deixa de privilegiar o mais eficiente.

Por sua vez, os impostos cumulativos também causam distorções típicas. Introduzem alterações nos preços relativos dos insumos, ainda que seus efeitos negativos sejam fortemente mitigados por terem alíquotas marginais baixas. Os tributos cumulativos são menos transparentes, pois se enraízam na produção e tornam-se invisíveis, exceção à última operação onde sua transparência é maior que a dos IVAs, pois esses últimos estão sempre embutidos nos preços das mercadorias.

No caso das exportações, os tributos cumulativos exigem métodos mais complexos de desoneração da produção, ainda que esse seja um problema técnico perfeitamente contornável se se dispuser de matrizes de relações interindustriais detalhadas. Basta investir em pesquisa e possuir a vontade para computá-las.

Um equívoco comum na avaliação de IMFs advém da presunção de que tributos cumulativos acumulam elevadas cargas tributárias geradas por "longas" cadeias de produção.

As cadeias de produção jamais podem ser descritas como "curtas" ou "longas": são sempre infinitas. Em realidade, qualquer produto ou serviço implica a contribuição de todos os demais setores da economia para sua produção. Trata-se de um processo circular e que necessariamente utiliza insumos de vários outros setores que, por sua vez, necessitam de insumos de outros setores, e assim sucessivamente. Portanto, a cadeia de produção não tem fim.

O que determina a carga de impostos de um tributo cumulativo é a relação entre insumos e valor agregado em cada estágio no processo de produção. Por exemplo, se um dado setor de produção compra insumos e agrega valor em montante equivalente, a cumulatividade carregada das etapas anteriores de produção acha-se totalmente embutida no valor dos insumos adquiridos. $\mathrm{O}$ valor agregado nesse estágio de produção não sofre qualquer efeito cumulativo nessa mesma etapa, passando a fazê-lo apenas na medida em que a produção se transforma em insumo na fase posterior de produção.

A Tabela 6 e o Gráfico 2 refletem esse fato, supondo-se uma taxa de agregação de valor (VA) equivalente a $100 \%$ do valor dos insumos adquiridos. No exemplo, supõe-se que o valor do produto final seja $R \$ 100$, incluído um imposto sobre movimentação financeira (IMF) de $1 \%$ no débito e no crédito bancários.

Os dados mostram que os efeitos da cumulatividade tributária se exaurem rapidamente ao se analisar o imposto carregado das etapas anteriores de 
produção, seguindo uma progressão geométrica decrescente, cuja razão pode ser vista na Tabela 6 . No exemplo dado, o valor total do imposto acumulado no preço do produto final é de $\mathrm{R} \$ 3,8646$, ou seja, a carga tributária equivale a $3,8646 \%$ do preço final.

Tabela 6

Impacto da tributação cumulativa por etapa da cadeia produtiva (Razão da progressão $=1 /(1+\mathrm{VA} \%)^{*}(1+\mathrm{IMF}) 2$ )

\begin{tabular}{|lcccc|}
\hline Período & $\begin{array}{c}\text { Preço final } \\
(\mathrm{R} \$)\end{array}$ & $\begin{array}{c}\text { Imposto por etapa } \\
(\mathrm{R} \$)\end{array}$ & $\begin{array}{c}\text { Valor agregado } \\
\text { (R\$) }\end{array}$ & $\begin{array}{c}\text { Insumo } \\
\text { (R\$) }\end{array}$ \\
\hline T & 100,0000 & 1,97039506 & 49,0148025 & 49,01480247 \\
T-1 & 49,01480247 & 0,96578525 & 24,0245086 & 24,02450861 \\
T-2 & 24,02450861 & 0,47337773 & 11,7755654 & 11,77556544 \\
T-3 & 11,77556544 & 0,23202516 & 5,7717701 & 7,77177014 \\
T-4 & 5,77177014 & 0,11372667 & 2,8290217 & 2,82902173 \\
T-5 & 2,82902173 & 0,05574290 & 1,3866394 & 1,38663941 \\
T-6 & 1,38663941 & 0,02732227 & 0,6796586 & 0,67965857 \\
T-7 & 0,67965857 & 0,01339196 & 0,3331333 & 0,33313331 \\
T-8 & 0,33313331 & 0,00656404 & 0,1632846 & 0,16328463 \\
T-9 & 0,16328463 & 0,00321735 & 0,0800336 & 0,08003364 \\
T-10 & 0,08003364 & 0,00157698 & 0,0392283 & 0,03922833 \\
T-11 & 0,03922833 & 0,00077295 & 0,0192277 & 0,01922769 \\
T-12 & 0,01922769 & 0,00037886 & 0,0094244 & 0,00942441 \\
T-13 & 0,00942441 & 0,00018570 & 0,0046194 & 0,00461936 \\
T-14 & 0,00461936 & 0,00009102 & 0,0022642 & 0,00226417 \\
T-15 & 0,00226417 & 0,00004461 & 0,0011098 & 0,00110978 \\
T-16 & 0,00110978 & 0,00002187 & 0,0005440 & 0,00054396 \\
T-17 & 0,00054396 & 0,00001072 & 0,0002666 & 0,00026662 \\
T-18 & 0,00026662 & 0,00000525 & 0,0001307 & 0,00013068 \\
T-19 & 0,00013068 & 0,00000257 & 0,0000641 & 0,00006405 \\
\hline
\end{tabular}

Nota-se que nas condições especificadas no exemplo a cumulatividade gerada ao longo da cadeia de produção se reduz rapidamente, atingindo valor de apenas cinco centavos de real na etapa T-5, caminhando rapidamente para valores próximos de zero. Percebe-se, assim, que a acumulação de tributos ocorre com intensidade bem menos alarmante do que fazem crer os críticos 
dos impostos sobre movimentação financeira. Na etapa T-3 o valor somado do imposto já representa $94 \%$ do seu total.

Gráfico 2

Imposto gerado por etapa na cadeia produtiva $(\mathrm{VA}=100 \%)$

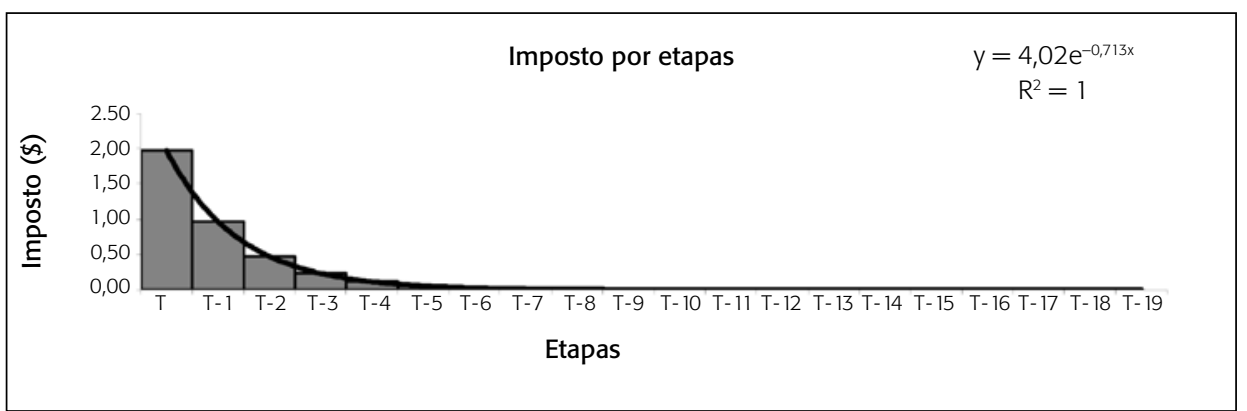

\section{Resumo das principais conclusões}

A situação previdenciária brasileira tem sido objeto de inúmeras e competentes análises, das quais tem resultado uma série de propostas de solução. Neste trabalho pretendeu-se apenas avaliar a proposta de uma nova forma de financiamento do RGPS, sem detalhamentos mais aprofundados sobre as causas e as características específicas das atuais dificuldades da previdência brasileira.

As conclusões podem ser resumidas nos seguintes tópicos:

Do ponto de vista macroeconômico, bem como para evitar a crescente informalização do mercado de trabalho e, consequentemente, o enfraquecimento das fontes de financiamento da previdência social, é aconselhável que se busque a imediata desoneração da folha de pagamentos das empresas de suas obrigações previdenciárias. Por ser fundamentalmente uma opção de política pública, e não uma escolha de seguro individual, os custos do INSS devem ser suportados por toda a sociedade, e não apenas pelos integrantes do mercado de trabalho, como aliás já previsto na Constituição brasileira.

Considerando a inviabilidade imediata da alteração do sistema previdenciário, e levando em conta os elevados custos de transição resultantes de uma mudança para um regime de capitalização, torna-se necessária a continuidade do sistema de repartição. Nesse caso, encontra-se mais uma justificativa conceitual para o deslocamento do fato gerador das contribuições previdenciárias da folha de salários (base de valor agregado) para o faturamento ou movimentação financeira (base cumulativa). 
Tem sido aventada a mudança do fato gerador das contribuições sociais ao INSS para o faturamento, para o lucro ou para a movimentação financeira. Sendo o lucro uma base de valor agregado declaratória, e já suficientemente tributado, a análise se resume à escolha entre o faturamento e a movimentação financeira, ambas cumulativas.

Bases tributárias cumulativas são comuns em todos os sistemas tributários, particularmente no brasileiro. Tributos cumulativos, bem como os de valor agregado, possuem vantagens e desvantagens do ponto de vista alocativo, distributivo, de economicidade e de simplicidade. Nas circunstâncias brasileiras, os tributos cumulativos possuem uma relação custo-benefício mais favorável, o que justifica a opção de desoneração da folha de salários das empresas através da transferência do fato gerador da contribuição social da base salarial para a movimentação financeira.

O faturamento representa o pior dos dois mundos, já que incorpora as desvantagens das bases declaratórias (complexidade burocrática, altos custos e estímulo à evasão e à sonegação) com os inconvenientes das bases cumulativas (maior complexidade para a adoção plena do princípio do destino no comércio externo e menor discricionariedade tributária).

A movimentação financeira mostra características positivas em economias como a brasileira. Além de sua simplicidade e baixos custos de conformidade e administrativos, ela introduz menos distorções alocativas do que tributos sobre valor agregado. A experiência da CPMF comprovou a eficácia e a capacidade arrecadatória desse tipo de tributo.

A movimentação financeira surge, portanto, como a melhor opção de base tributária para substituir as incidências sobre folha de pagamentos das empresas no financiamento do RGPS. A CMF implica menor carga tributária setorial comparativamente ao INSS e ainda introduz menos distorções nos preços-relativos.

Trata-se de um tributo mais eficiente do que a atual incidência sobre folha de pagamentos das empresas.

\section{Referências}

BIRD, R.M.; GENDRON, P.-P. Imposto de valor agregado em estados federais: retrospecto internacional e novas perspectivas. In: O Brasil e a Alca: tributação e integração. São Paulo: Sinafresp, 2001.

CINTRA, M. Imposto único sobre transações (IUT). In: CINTRA, Marcos (Org.). Tri- 
butação no Brasil e o imposto único. São Paulo: Makron Books, 1994. p. 203-245. . A sonegação é o x do problema. O Globo, Rio de Janeiro, 14 maio 2001. . A verdade sobre o imposto único. São Paulo: LTCE Editora, 2002. . Bank transactions: pathway to the single tax ideal. São Paulo: Cyan Artes Gráficas, 2009.

DOMINGUES, E.P.; HADDAD, E.A. Política tributária e relocalização. Revista Brasileira de Economia, Rio de Janeiro, v. 57, n. 4, out./dez. 2003.

ECKSTEIN, Otto. Public finance. New Jersey: Prentice Hall Inc., 1964.

ERIS, C.C.C.; ERIS, I. Incidência e peso morto de impostos no contexto do modelo generalizado de Leontief: uma exposição geométrica. In: ERIS, C.C.C. et al. (Org.). Finanças públicas. São Paulo: Pioneira/Fipe, 1983.

KAY, J. A. Tax policy: a survey. The Economic Journal, v. 100, n. 399, mar. 1990. LIPSEY, R.G.; LANCASTER, K. The general theory of second-best. Review of Economic Studies, v. 24, n. 1, p. 11-32, 1956/57.

MACIEL, E. Reforma tributária e federalismo no Brasil. Palestra proferida na Federação de Indústrias de Brasília, 7 ago. 2001. Disponível em: <www.marcoscintra. org $>$.

MINISTÉRIO DA PREVIDÊNCIA E ASSISTÊNCIA SOCIAL. Livro branco da Previdência Social. Brasília: Ministério da Previdência e Assistência Social, 2002.

SECRETARIA DA RECEITA FEDERAL. Consolidação da declaração do IRPJ. Brasília, mar. 2006.

SILVA, P.L.B.; MELO, M.A.C. Reforma da seguridade social no Brasil. Campinas: Universidade Estadual de Campinas (Unicamp), Núcleo de Estudos de Políticas Públicas (NEPP), fev. 1999. n. 39.

A SURVEY of globalization and tax: the mystery_of the vanishing taxpayer. The Economist, London, 27 Jan. 2000.

VARSANO, R. et al. Substituindo o PIS e a Cofins - e por que não a CPMF? - por uma contribuição não cumulativa. Rio de Janeiro: Ipea, Ministério do Planejamento, Orçamento e Gestão, out. 2001. Texto para discussão n. 832. 